\title{
Crust and upper mantle structures beneath Northeast China from receiver function studies
}

\author{
Zhen Guo $\cdot$ Yuliang Cao $\cdot$ Xianguang Wang $\cdot$ \\ Y. John Chen · Jieyuan Ning $\cdot$ Weiguang He $\cdot$ \\ Youcai Tang $\cdot$ Yongge Feng
}

Received: 18 December 2013/Accepted: 6 March 2014/Published online: 13 May 2014

(C) The Seismological Society of China, Institute of Geophysics, China Earthquake Administration and Springer-Verlag Berlin Heidelberg 2014

\begin{abstract}
P-wave and S-wave receiver function analyses have been performed along a profile consisted of 27 broadband seismic stations to image the crustal and upper mantle discontinuities across Northeast China. The results show that the average Moho depth varies from about $37 \mathrm{~km}$ beneath the Daxing' anling orogenic belt in the west to about $33 \mathrm{~km}$ beneath the Songliao Basin, and to about $35 \mathrm{~km}$ beneath the Changbai mountain region in the east. Our results reveal that the Moho is generally flat beneath the Daxing'anling region and a remarkable Moho offset (about $4 \mathrm{~km}$ ) exists beneath the basin-mountain boundary, the Daxing'anling-Taihang Gravity Line. Beneath the Tanlu faults zone, which seperates the Songliao Basin and Changbai region, the Moho is uplift and the crustal thickness changes rapidly. We interpret this feature as that the Tanlu faults might deeply penetrate into the upper mantle, and facilitate the mantle upwelling along the faults during the Cenozoic era. The average depth of the lithosphereasthenosphere boundary (LAB) is $\sim 80 \mathrm{~km}$ along the profile which is thinner than an average thickness of a continental lithosphere. The LAB shows an arc-like shape in the basin, with the shallowest part approximately beneath the center of the basin. The uplift LAB beneath the basin might be related to the extensive lithospheric stretching in the
\end{abstract}

\footnotetext{
Z. Guo $\cdot$ Y. Cao $\cdot$ X. Wang $\cdot$ Y. John Chen $(\bowtie) \cdot$ J. Ning ·

W. He $\cdot$ Y. Feng

School of Earth and Space Sciences, Institute of Theoretical and Applied Geophysics (ITAG), Peking University, Beijing 100871, China

e-mail: johnyc@pku.edu.cn

Y. Tang

State Key Laboratory of Petroleum Resource and Prospecting, and Unconventional Natural Gas Institute, China University of Petroleum, Beijing, China
}

Mesozoic. In the mantle transition zone, a structurally complicated $660 \mathrm{~km}$ discontinuity with a maximum $35 \mathrm{~km}$ depression beneath the Changbai region is observed. The $35 \mathrm{~km}$ depression is roughly coincident with the location of the stagnant western pacific slab on top of the $660 \mathrm{~km}$ discontinuity revealed by the recent $\mathrm{P}$ wave tomography.

Keywords Northeast China - NCC .

Receiver function - Migration - CCP · Moho - LAB . Mantle transition zone

\section{Introduction}

Northeast China (hereafter NE China) is a significant region to understand the intraplate volcanism and the interaction of subducted oceanic plate in the mantle transition zone with overlying tectonic structure (Chen and Pei 2010). NE China has experienced a complex tectonic evolution and magmatic history related to the collision of Okhotsk ocean in northeast and the westernward subduction of the Pacific plate (Contour lines in Fig. 1) at the Japan trench subduction in southeast (Hilde et al. 1977; Meng et al. 2003; Ren et al. 2002; Zorin et al. 1993). The rifting process took place and the Songliao Basin formed during the late Jurassic and early Cretaceous ( $\mathrm{Hu}$ et al. 1998). In the Cenozoic, NE China is characterized by large scale strike slip faults, rifts, and active intraplate continental magmatism (Ren et al. 2002). The Cenozoic volcanism is widely distributed in the Songliao basin and particularly along the valleys and mountain belts on the flanks of the basin (Fig. 1) (Liu et al. 2001).

NE China lies between two acient cratons: North China Craton (NCC) and the Siberian plate (Fig. 1). The eastern part of NCC has undergone large-scale lithospheric 


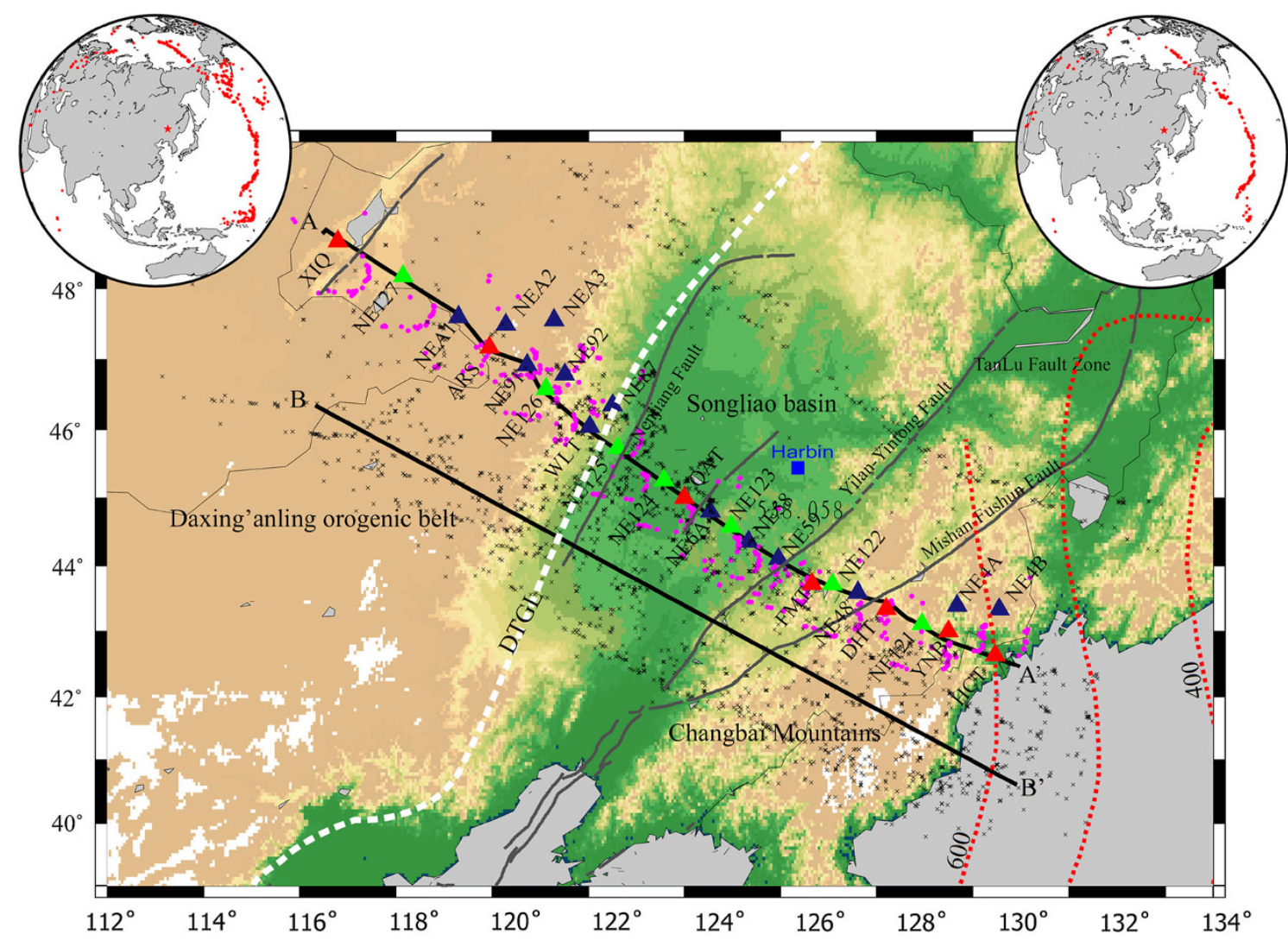

Fig. 1 Map of study region showing tectonic setting of Northeast China and the locations of broadband seismic stations used in this study. Teleseismic waveform data are collected from seven PKU stations (green triangles in the figure), thirteen NECESSArray stations (blue triangles), and seven permanent CEA stations (red triangles). Black crosses are piercing points of converted Ps wave in $700 \mathrm{~km}$. Line A-A' mark the profiles to image the Moho and the LAB variations and line B- ${ }^{\prime}$ is for imaging the mantle transition discontinuities. Teleseismic events used to get $\mathrm{P}$ and $\mathrm{S}$ wave receiver functions are shown in the upper left and right panels, respectively. Major tectonic setting in Northeast Eurasia is also marked including Daxing' anling-Taihang Gravity Line (DTGL), subducted pacific plate (marked by red depth contour)

removal during the Phanerozic (Griffin et al. 1998). The NE China consists of Daxing'anling orogenic belt, Changbai mountain region and the Songliao Basin. The Songliao basin is characterized as rift basin, thick sediments $(\sim 5-6 \mathrm{~km})$ in center, and oil deposit (Hu et al. 1998). The dramatic topographic offset between the Daxing'anling and Songliao basin is known as the Daxing'anling-Taihang Gravity Line (DTGL), which is consistent with the rapid change of gravity and crustal thickness. The Songliao basin is bounded by Yi-Yi faults and Fu-Mi faults in east, which are northeastern elongation of Tanlu Faults Zone (hereafter Tanlu faults) and are believed to have facilitated the local upwelling of the asthenospheric mantle (Xu 2001; Xu et al. 2004).

NE China has been the subject of numerous geophysical studies. Previous receiver functions studies in NE China have revealed significant variations within lithosphere and mantle transition zone discontinuities (Liu and Niu 2011). Lithospheric thickness analysis in NE China comes mostly from seismic tomography imaging so far, which is insufficient to allow the identification of a fine interface structure ( $\mathrm{Li}$ et al. 2012). Recent tomographic models (Fukao et al. 2001; Lei and Zhao 2005; Pei and Chen 2010) reveal a stagnant subducted Pacific slab at the bottom of the mantle transition zone instead of sinking into the lower mantle beneath NE China. A 20-35 km depression of the $660 \mathrm{~km}$ discontinuity corresponding to the stagnant slab was also observed from receiver function common conversion point (CCP) stacking. Due to sparseness of seismic stations in the region, previous mantle transition zone studies were mainly focused on the eastern portion of NE China (Ai et al. 2003; Li and Yuan 2003). So controversies over the westward extent of the stagnant slab in the mantle transition zone and its impact on the transition zone discontinuities morphologies still exist (Chen and Pei 2010; Li and Yuan 2003). Taking the advantage of a more widely and densely deployed stations in the most recent NECESSArray, we can get much more detailed lateral changes of the crustal and upper mantle discontinuities in the whole study region. The results will help us to better define the subducted pacific plate as well as its impact on the overlying continental plate. 
In this study, we used receiver function imaging techniques to image upper mantle and mantle transition zone structures beneath the NE China. Receiver function analysis is now a routine method for the crustal and mantle interfaces studies. It detects discontinuities by identifying the arrival time difference between direct $\mathrm{P}$ and converted Ps phases generated at these discontinuities (Dueker and Sheehan 1997; Langston 1977; Wu et al. 2007). The interference of the crustal multiple with the converted phase at the lithosphere-asthenosphere boundary (LAB) makes it difficult to distinguish the LAB from $P$ wave receiver functions. The recently developed $S$ wave receiver function analysis overcomes the interference problem, and can resolve smaller scale LAB structures compared with other seismic techniques (Chen et al. 2006, 2008; Farra and Vinnik 2000).

\section{Data and method}

In this study, we collected teleseismic waveform data from 27 seismic stations along a profile across the study region. The profile includes 7 PKU stations, 7 permanent CEA stations and 13 NECESSArray stations. The PKU stations were operated from September 2010 to August 2011, the NECESSArray stations ran for 2 years from September 2009 to August 2011, and CEA stations also spanned for two years from 2009 to 2011.

We selected $\mathrm{P}$ waves with high signal-to-noise ratios and epicentral distances between $30^{\circ}$ and $90^{\circ}$ and magnitude $>5.5 \mathrm{Mb}$. A time window of $20 \mathrm{~s}$ before and $120 \mathrm{~s}$ after the $\mathrm{P}$ wave arrival was used. All raw data pre-filtered with a bandpass filter of $0.1-2.5 \mathrm{~Hz}$. Receiver functions were obtained using the iterative deconvolution method (Ligorría and Ammon 1999). We found that for the Moho imaging, the Gaussian parameter of 3 with water lever of 0.001 is suitable, while for the mantle transition zone, we selected Gaussian parameter of 1.0. For most of the stations, more than $90 \mathrm{P}$ receiver functions were selected after visual inspection and finally 2,375 $\mathrm{P}$ receiver functions were obtained. The distributions of the events used in the $\mathrm{P}$ receiver functions are illustrated in left-upper panel of Fig. 1. The piercing points of converted phase of $\mathrm{P}$ receiver functions at $700 \mathrm{~km}$ are also shown in Fig. 1.

$\mathrm{S}$ waveform with epicentral distance from $50^{\circ}$ to $85^{\circ}$ and magnitude $\geq 5 \mathrm{mb}$ (Yuan et al. 2006) is selected to obtain the $S$ wave receiver functions. Since $S$ waves are sometimes interfere with $\mathrm{P}$ coda and are characterized as low signal-to-noise ratios, visual inspection is conducted to select clear $\mathrm{S}$ waves before deconvolution ( $\mathrm{Li}$ et al. 2004). We applied the free surface correction (Kennett 1991) to extract the incident $\mathrm{P}$ and converted $\mathrm{S}$ waves from the vertical and radial component waveforms. The bandpass filter with corner frequency from 0.05 to $0.5 \mathrm{~Hz}$ is applied to the raw waveforms. The $\mathrm{S}$ receiver functions are then obtained by deconvolving the SV component from the $\mathrm{P}$
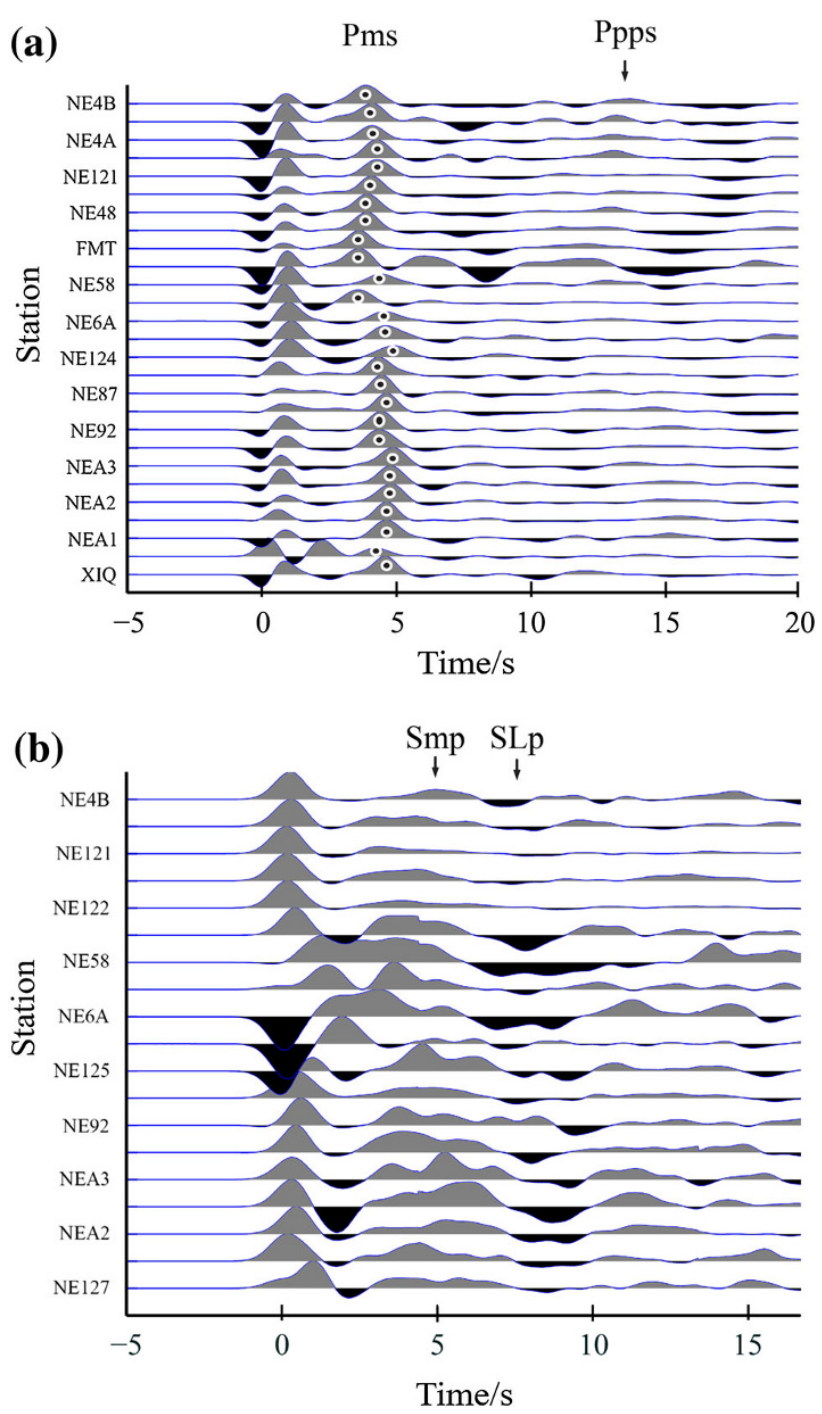

Fig. 2 Move-out corrected $\mathrm{P}$ wave (a) and $\mathrm{S}$ wave (b) receiver functions. All traces are stacked and normalized. Positive amplitudes are shaded in gray, while negative in black. Station names are plotted at the left of each trace. Primary Moho converted phase Pms and Smp can be identified clearly in all traces. Although very weak, multiple phases like Ppps can still be tracked in most seismograms. Because of the interference of multiple phases in sediments in $\mathrm{P}$ wave receiver functions, $\mathrm{LAB}$ converted phases can only be identified in $\mathrm{S}$ wave receiver functions

component using the same time domain deconvolution method with the $\mathrm{P}$ wave receiver functions analysis. After deconvolution, erratic traces were visually removed, finally resulting in a total of 729 useful $\mathrm{S}$ receiver functions.

To illustrate the different waveform features of receiver functions across the profile, we move-out corrected all $\mathrm{P}$ and $S$ receiver functions (Yuan et al. 1997), and then normalized and stacked them at each station (Fig. 2). The primary Moho conversions (Pms or Smp) can be clearly identified in both stacked $\mathrm{P}$ and $\mathrm{S}$ receiver functions. Negative signals related to the LAB at 8-10 s exist after the primary Moho conversions at most stations (Fig. 2b). 
The LAB-related phases are hard to trace in stacked $\mathrm{P}$ receiver functions (Fig. 2a). Therefore, we only used $S$ wave receiver functions to construct features of the LAB. For stations in the Songliao basin, significant waveform variations were obtained in both stacked $\mathrm{P}$ and $\mathrm{S}$ receiver functions, indicating the strong influence of the thick sediment in the basin. Moho multiples such as Ppps and Ppss + Psps can be tracked clearly in stacked $\mathrm{P}$ wave receiver functions, so multiple waves were also used in the $\mathrm{P}$ wave migration to image the Moho.

In order to obtain a more detailed image of Moho and LAB, we applied the Kirchhoff style migration methodology developed by Wilson (Wilson and Aster 2005) to image the Moho and the LAB. The method characterizes the output model as a grid of point scatterers. For each station, we backprojected receiver function arrivals to all possible scattering points within the model space. Waveform amplitudes are weighted and stacked according to the Kirchhoff integral. The method avoids the assumption of the flat layer, and significantly improves resolution relative to CCP stacking (Chen et al. 2005; Ryberg and Weber 2000). For P receiver functions, multiple modes generated by thick sediments are in the window of the Pms (P-to-s conversion at the Moho), so it is difficult to discern the Moho that is actually migrated from Pms phases, or is improperly from shallower multiples in the region with thick sediments. The Moho related multiple PpPs can be used to remove this ambiguity. Interpolated CUB2.0 global velocity models were used in the migration (Shapiro and Ritzwoller 2002) for each station, and station elevations are also corrected for each receiver function (Yue et al. 2012). Both $P$ and $S$ receiver functions are migrated along the profile $A-A^{\prime}$.

We use a common conversion point stacking method (CCP) of $\mathrm{P}$ receiver functions to produce an image of the mantle transition zone discontinuities. All $\mathrm{P}$ receiver functions are move-out corrected and then converted from time domain to the depth domain, assuming a horizontally layered medium. We used ak135 velocity model with modified crust by CRUST2.0 as the reference velocity model. We stacked the receiver functions into circular bins according to their piercing points at difference depth, with the gaussian weighting scheme applied to each waveform. The piercing points spread over greater area with increasing depth, so we increase the size of each bin with depth from $110 \mathrm{~km}$ at $400 \mathrm{~km}$ to $200 \mathrm{~km}$ at $700 \mathrm{~km}$.

\section{Results and discussions}

\subsection{Lithospheric structures}

Figures 3 and 4 show the depth of the Moho and the LAB from migrated $\mathrm{P}$ wave and $\mathrm{S}$ wave receiver functions across the section, respectively. The migrated Ps and PpPs phases to image the Moho are shown in Figs. 3a, b. The most conspicuous features in Fig. $3 \mathrm{a}$ are Ps phases generated at the Moho, occurring prominently at $20-40 \mathrm{~km}$ depth across the entire profile. The first order Moho features resolved by the migrated $\mathrm{Ps}$ conversions, $\mathrm{P}$ wave multiple reflections from $\mathrm{P}$ receiver functions, and $\mathrm{Sp}$ conversions from $\mathrm{S}$ receiver function are all similar. Some inconsistencies of Moho features between $\mathrm{P}$ receiver and $\mathrm{S}$ receiver functions are caused by the low frequency content of $\mathrm{S}$ wave, which may smear the Moho into broader and weaker zone. The migrated stacking of $P$ receiver functions indicates a rather thin and flat Moho (about $34 \mathrm{~km}$ ) across the entire transect, particularly, in the Daxing'anling region. The profile can be divided into three sub-sections: the Daxing'anling orogenic belt, the Songliao basin, and the Changbai mountain region.

The Daxing' anling orogenic belt has relatively deeper and flatter Moho depth compared with other two sub-sections. However, the Daxing'anling orogenic belt has an approximate $1 \mathrm{~km}$ altitude variation and an elevation that is more than $1.2 \mathrm{~km}$ higher than the Songliao basin (top panel in Fig. 3). Assuming crustal and mantle densities of 2.7 and $3.3 \mathrm{~g} / \mathrm{cm}^{3}$, approximately $0.3 \mathrm{~km}$ additional elevation of topography needs about $1.5 \mathrm{~km}$ additional crustal thickness to keep the isostatic balance. This suggests that the high elevation of the mountain regions is not fully compensated by the relatively flat crust. The crustal thickness varies from about $37 \mathrm{~km}$ in the Daxing' anling region to about $33 \mathrm{~km}$ in the Songliao basin. We observe a Moho offset of $\sim 4 \mathrm{~km}$ at the mountain-basin boundary, roughly beneath the DTGL. The Moho offset beneath the DTGL was also observed in the previous studies by active seismic exploration in the region (Yang et al. 1996). In their study, the Moho locates at about $40 \mathrm{~km}$ in the Daxing' anling orogenic belt and $35 \mathrm{~km}$ in the eastern portion of the Songliao basin.

The Moho beneath the Songliao basin shallows gradually from $33 \mathrm{~km}$ at the DTGL to $26 \mathrm{~km}$ at the Tanlu faults. Strong multiple modes can be seen in some stations in the center of the basin, where the sediment is as thick as 5-6 km. The most striking feature of crustal thickness in the basin is that rapid Moho depth undulation (3-5 km) exists beneath the Tanlu faults. The migrated image of the Ps conversions and PpPs multiple mode shows the similar feature beneath Tanlu faults, which means that this apparent Moho variation is robust. Another interesting feature in the Songliao basin is that the thinnest crust is beneath Tanlu faults $(\sim 26 \mathrm{~km})$ rather than beneath the central Songliao basin $(\sim 30 \mathrm{~km})$. The shallow Moho beneath the Tanlu faults in the region is also suggested by previous receiver function studies (Liu and Niu 2011). In the Changbai mountain region, the Moho dips monotonically from $\sim 26 \mathrm{~km}$ to $\sim 33 \mathrm{~km}$ from west to east. 
(a)
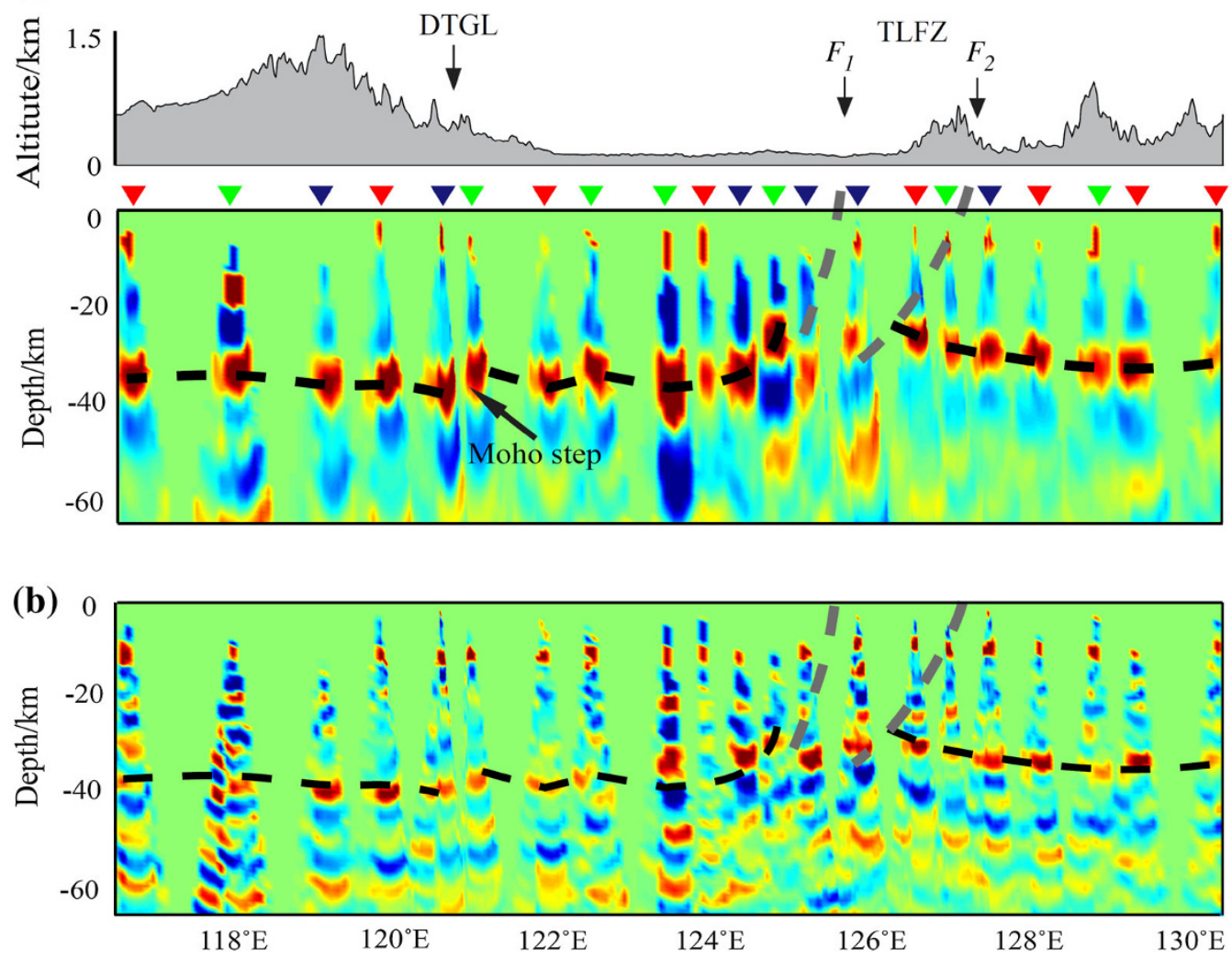

Fig. 3 Migrated $\mathrm{P}$ (a) and Ppps (b) along profile $A-A^{\prime}$. Surface topography along the line is plotted at the top. Black arrow denotes the 4-5 km offset in DTGL. Two parallel faults of the Tanlu fault zone are also marked by $F_{1}$ and $F_{2}$. Rapid Moho depth change exists beneath Tanlu fault zone (TLFZ)

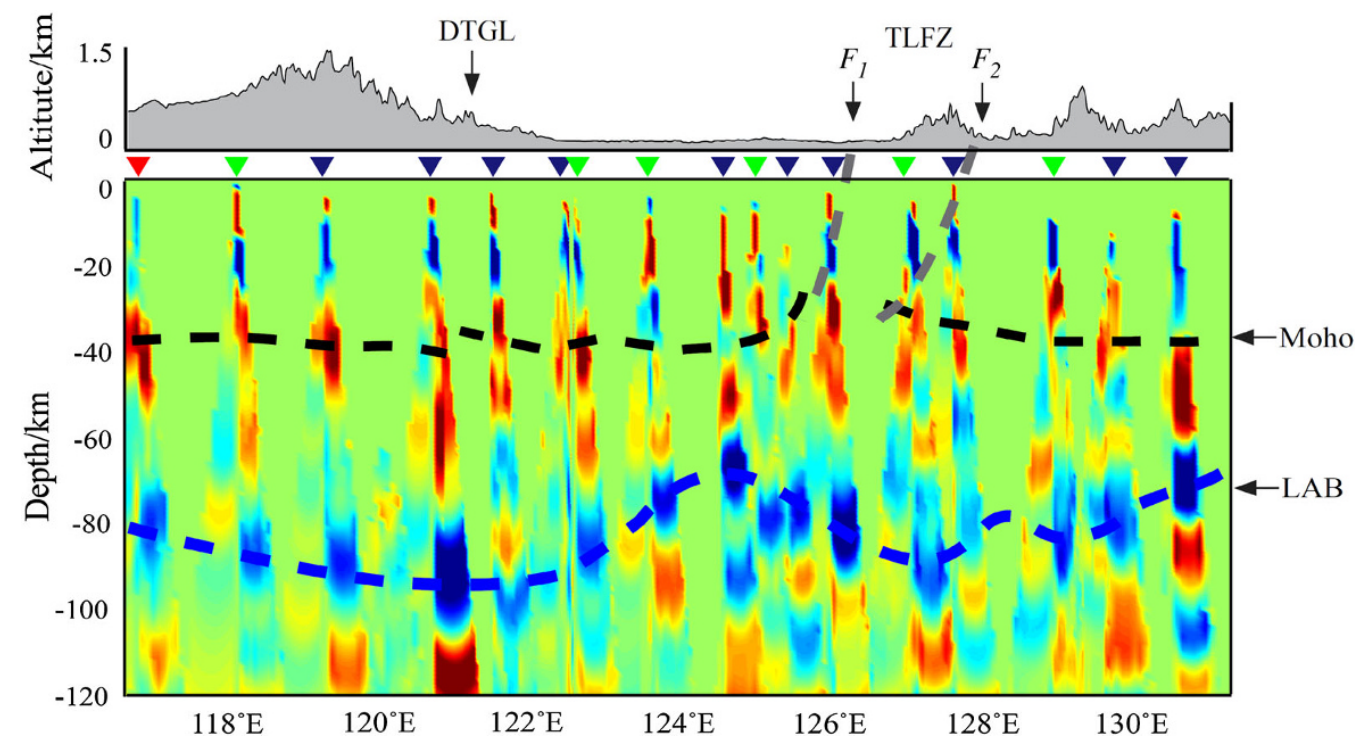

Fig. 4 Migrated S-wave receiver functions along profile $A-A^{\prime}$. The black dashed line denotes the Moho depth variation from migrated P-wave receiver functions shown in Fig. 3. The thick blue dashed line denotes the LAB variation along the profile. Note that in the Songliao Basin, the $\mathrm{LAB}$ exhibits an arc shape with its peak approximately beneath the center of the basin 
The undulating and uplift Moho beneath the Tanlu faults is probably the evidence for the faults penetrating into the uppermost mantle (Chen et al. 2006). In Cenozoic, the Tanlu faults experienced extensive volcanic activities, and the volcansim occurred in an episodic and sporadic manner (Liu et al. 2001). The Cenozoic volcanism is most mantlederived, consisting of alkali basalts and tholeiitic basalts with the age ranging from about 80 Ma to about 300 years ago (Wu et al. 2003). The petrological and geochemical studies of the Cenozoic basalts suggest the widespread mantle upwelling happened along the the Tanlu faults in the Cenozoic (Liu et al. 2001; Wu et al. 2003). The deeply penetrated faults acted as a channel and facilitated the ascending of asthenosphere and the upwelling caused uplift of the Moho beneath the faults zone (Liu and Niu 2011). The Cenozoic mantle upwelling is generally believed to be related with the subduction of the Pacific plate (Liu et al. 2001; Ren et al. 2002). The big mantle wedge convection model is a promising candidate to explain the Cenozoic upwelling. The model hypothesizes that the complex tectonic history of the subducted Pacific plate could have caused a mantle convection in the extended mantle wedge, and the convection either transport the melt generated above the transition zone to the upper mantle beneath NE China or caused the local asthenospheric melting to feed the volcanism along the faults zone in Cenozoic (Chen and Pei 2010).

The $\mathrm{Sp}$ mode generated at the LAB is also evident at $60-100 \mathrm{~km}$ in Fig. 4 across the transect $A-A^{\prime}$. The $\mathrm{S}$ receiver functions with dominant period longer than $5 \mathrm{~s}$, corresponding to a wavelength of $\sim 20 \mathrm{~km}$, can resolve a LAB with $5 \%$ velocity contrast and $\sim 20 \mathrm{~km}$ sharpness (Li et al. 2007). Due to the strong shear wave attenuation in the mantle, $\mathrm{S}$ receiver function migration is characterized by lower lateral resolution to image the Moho compared with the $\mathrm{P}$ receiver function migration. A thinner lithosphere compared with the global continental average is found beneath the study region with depth varying between $60 \mathrm{~km}$ and $100 \mathrm{~km}$. The LAB dips monotonically from $80 \mathrm{~km}$ at the western edge of the profile in Daxing'anling to $\sim 100 \mathrm{~km}$ at the DTGL, and then it shallows by $\sim 35 \mathrm{~km}$ over a distance of about $250 \mathrm{~km}$ to the Songliao basin, with the sharpest gradient at the basin-mountain boundary (DTGL). In the Songliao basin, the LAB displays an accurate shape with the shallowest part ( $\sim 65 \mathrm{~km}$ ) beneath the central basin. It becomes deeper to both sides, reaching $90 \mathrm{~km}$ at the basin-Changbai boundary in the west and $\sim 100 \mathrm{~km}$ at the Daxing'anling. The lithospheric thickness shallows from $\sim 90 \mathrm{~km}$ beneath the Tanlu faults to $\sim 70 \mathrm{~km}$ at the eastern boundary of the profile in Changbai mountain region.

The thinned lithosphere in the Songliao basin was also suggested by the previous studies using comprehensive geophysical methods. Their results showed that the shallowest point of asthenosphere in the Songliao basin is about $60 \mathrm{~km}$ at present (Yang et al. 1996). The surface wave tomography (Liu and Niu 2011) also indicates a sharp lithospheric thickness change beneath the DTGL with a low lateral resolution. Our results provide a more concrete and detailed evidence to support the thin lithosphere speculation beneath the Songliao basin. The thin lithosphere in the Songliao basin also agrees with the relatively high geothermal gradient with a maximum of $6.2^{\circ} \mathrm{C} / 100 \mathrm{~m}$ and an average heat flow $2.24 \mathrm{HFU}$ (Ren et al. 2002). We suggest that the thinned and arch-shaped lithosphere beneath the Songliao basin observed by our study is caused by the lithospheric stretching in the Mesozoic. In the late Mesozoic, the NE China experienced large-scale lithospheric extension, and the Songliao basin formed by the subsequent thermal subsidence (Ren et al. 2002). The extension is recorded by the occurrence of rift basins, metamorphic core complex, and is accompanied by widespread volcanism (Meng et al. 2003). The mechanism and dynamic trigger of the lithospheric thinning of the NE China during the Meozoic are still controversial (Tian et al. 1992). Several models have been proposed to account for it, including the backarc spreading related to the subducting of the paleo-Pacific plate, and the breakoff of the northward subducting Mongol-Okhotsk oceanic slab trigged extension (Meng et al. 2003; Ren et al. 2002).

In the Changbai mountain region, a relatively thin lithosphere and crust are also observed, with the relatively high topography (about $1 \mathrm{~km}$ ). The gravity modeling suggests that the observed thin crust could not compensate the gravity decrease in this region (Liu and Niu 2011). Liu and Niu (2011) introduced a thermal upwelling model to explain the Moho uplift, and the depth extension of the upwelling is estimated to be $\sim 100 \mathrm{~km}$. In this study, our Moho and LAB models are consistent with the speculation.

\subsection{Mantle transition zone structures}

The mantle transition zone discontinuities at 410 and $660 \mathrm{~km}$ depths are global structures related to the mineral phase transformations. The $410 \mathrm{~km}$ discontinuity represents the phase transformation from $\alpha$-olivine $\beta$-spinel, and the $660 \mathrm{~km}$ discontinuity represents transformation of $\gamma$ spinel to perovskite and magnesio-wüstite (Ito and Takahashi 1989; Jackson 1983). Because of the positive and negative Clapeyron slops of these two phase transforms, relatively low temperature of the subducted plate in subduction region causes a relatively thicker mantle transition zone, with elevated $410 \mathrm{~km}$ and depressed $660 \mathrm{~km}$. While in plume region, hot material will cause a thinner transition zone, with depressed $410 \mathrm{~km}$ and elevated $660 \mathrm{~km}$. If cold material of subducted plate piles up at the top of the 


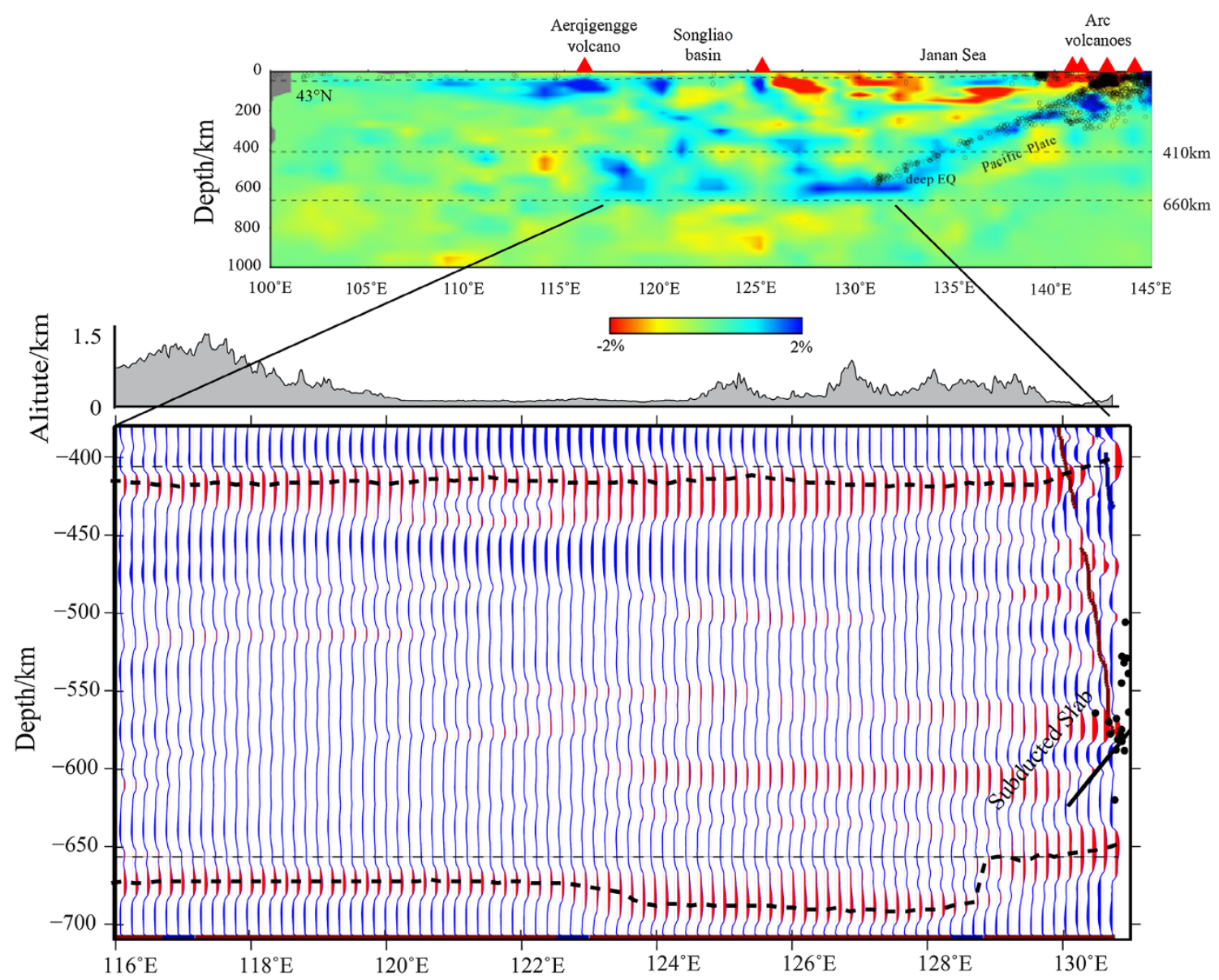

Fig. 5 Profile of CCP image of 410 and $660 \mathrm{~km}$ discontinuities from B-B'. The top inset shows regional tomography from Pei and Chen (Pei and Chen 2010). The morphology of the subducted slab is indicated by the black line and deep earthquakes in the mantle transition zone are marked by the black dots

$660 \mathrm{~km}$, it should cause the $660 \mathrm{~km}$ deepening over a large area. Otherwise, if the subducted plate penetrates through the $660 \mathrm{~km}$ and sinks into the lower mantle, a significant $660 \mathrm{~km}$ deepening will occur in a narrow region near the slab (Li and Yuan 2003). Figure 5 shows the topographic variation of the 410 and $660 \mathrm{~km}$ discontinuities (hereafter 410 and $660 \mathrm{~km}$ ) by using CCP stacking method. From $132^{\circ} \mathrm{E}$ to $129^{\circ} \mathrm{E}$, depth of $660 \mathrm{~km}$ is exactly equal to the global average. The $660 \mathrm{~km}$ significant depressed $\sim 35 \mathrm{~km}$ near $129^{\circ} \mathrm{E}$. The depression continues to $123^{\circ} \mathrm{E}$ and then the $660 \mathrm{~km}$ shallows from $\sim 700 \mathrm{~km}$ to $\sim 680 \mathrm{~km}$ at $125^{\circ} \mathrm{E}$, still $\sim 20 \mathrm{~km}$ deeper than the average. Complicated inner mantle transition zone structures are observed in the eastern portion of the profile, at the depth range of 500-650 km, right above the observed $\sim 35 \mathrm{~km}$ depressed $660 \mathrm{~km}$ zone. Unlike the fluctuant $660 \mathrm{~km}$ along the profile, the $410 \mathrm{~km}$ shows little fluctuation in the depth range of 415-420, $\sim 5-10 \mathrm{~km}$ deeper than global reference depth. The deepening of the $410 \mathrm{~km}$ discontinuity was also observed in separate studies in East China (Ai et al. 2003). The inaccurate reference velocity models of the upper mantle may cause the 410 and $660 \mathrm{~km}$ coherently shifted. In general, if we use the higher velocity model than the actual one in upper mantle, the apparent mantle transition zone interfaces will be deeper than the real depth. The tomographic result in upper panel of Fig. 5 shows low velocity anomaly above the mantle transition zone (Chen and Pei 2010). We suggest the observed deepening of $410 \mathrm{~km}$ over these regions is caused by the accumulated effects of these slow velocities above the mantle transition zone. One way to remove potential systematic errors in the upper mantle velocity model is to calculate the mantle transition zone thickness, which is the difference between the absolute depths of the 410 and $660 \mathrm{~km}$ discontinuities, can be constrained fairly well without knowing the exact velocity structure of the overlying mantle (Owens et al. 2000).

Two large thickness gradient zones are observed at $129^{\circ} \mathrm{E}$ and between $123^{\circ} \mathrm{E}$ and $124^{\circ} \mathrm{E}$ in Fig. 6. The most significant one in $129^{\circ} \mathrm{E}$ spans over a distance of less than $100 \mathrm{~km}$, is in the order of $35 \mathrm{~km}$. The general thickened mantle transition zone gradually varies from $>270 \mathrm{~km}$ 


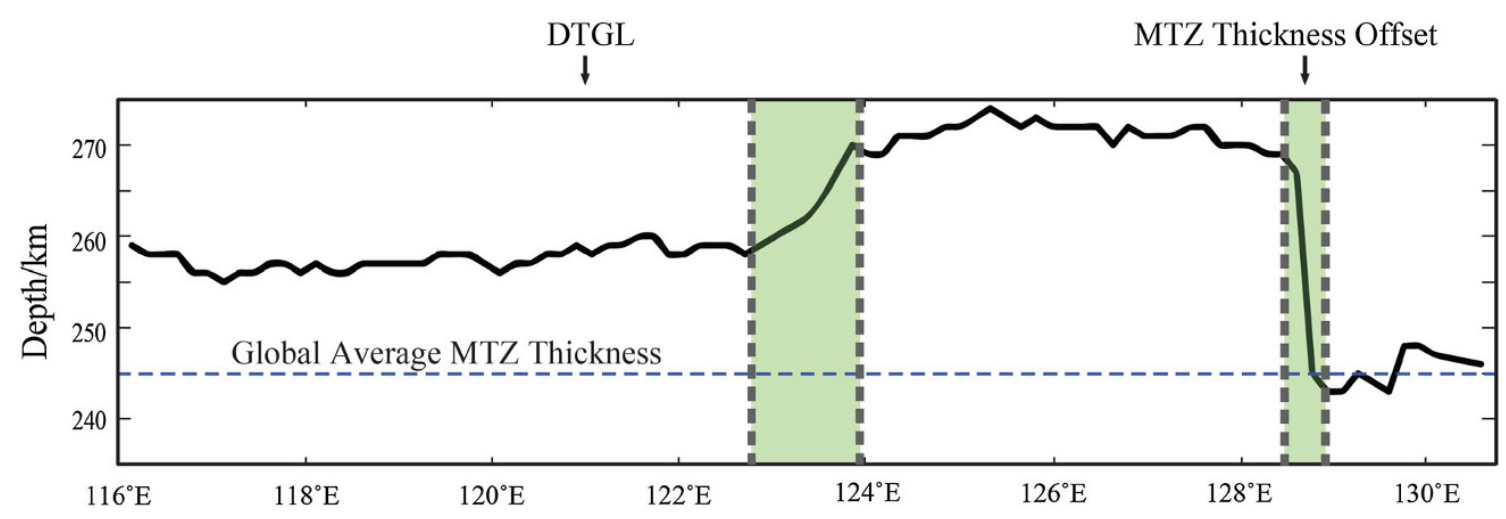

Fig. 6 Thickness of the mantle transition zone. The black arrow marks the location of a sharp thickness change of the mantle transition zone. The blue line represents the global average thickness of the mantle transition zone. Green color represents the most significant thickness change of the mantle transition zone

between $128^{\circ} \mathrm{E}$ and $124^{\circ} \mathrm{E}$ to about $255 \mathrm{~km}$ in the western portion of the profile. If we assume that the topography of the thickening of the transition zone is caused solely by a temperature effect and use a Clapeyron slops of $+2.9 \mathrm{Mpa} / \mathrm{K}$ for $410 \mathrm{~km}$ and $-1.9 \mathrm{Mpa} / \mathrm{K}$ for $660 \mathrm{~km}$, then over $20-30 \mathrm{~km}$ of variation of the thickness would require a temperature higher anomaly of about $150-200 \mathrm{~K}$ relative to the ambient mantle (Bina and Helffrichl 1994). The thickening of the mantle transition zone across the profile could be explained by the presence of the stagnant Pacific slab and over $500 \mathrm{~km}$ thickening of mantle transition zone between $128^{\circ} \mathrm{E}$ and $124^{\circ} \mathrm{E}$ suggests that the subducted slab piles up at the top of the $660 \mathrm{~km}$ rather than penerates into the lower mantle. The $\sim 35 \mathrm{~km}$ thickened mantle transition zone is also concordance with the previous observations in the region, which they interpreted as the evidence that the slab penetrating into the lower mantle locally (Li and Yuan 2003), but from the regional $P$ wave tomography (Chen and Pei 2010; Pei and Chen 2010), the large and continuous slab-like high velocity anomalies correlating with our results well (upper panel of Fig. 5). Some inconsistencies of the slab position revealed by the tomography and the receiver functions might be caused by the intrinsic low resolution at mantle transition zone of the teleseismic body wave tomography and tomographic horizontal smearing effects. From $116^{\circ} \mathrm{E}$ to $124^{\circ} \mathrm{E}$, the $\sim 15 \mathrm{~km}$ thickening of the transition zone correlates well with fast anomalous fragments at tomography image, which could provide the evidence that these remnants are robust features in the transition zone. The observed slab remnants are suggested causing by the retreating of the Pacific plate in the Cenozoic (Chen and Pei 2010).

Depth extents of the crustal and upper mantle discontinuities, including the Moho (crustal thickness), the LAB (lithospheric thickness), and 410 and $660 \mathrm{~km}$ interfaces (mantle transition zone structures), are the indispensable features to understand the interaction of subducted slab and the upper mantle in NE China. To compare the structural variations at different depth levels and correlate with the surface deformation of the NE China, we plot the Moho, the LAB, and the mantle transition zone thickness against topography of the NE China in Fig. 7. A sharp change in elevation of over $1.2 \mathrm{~km}$ corresponding to the DTGL well correlates with the abrupt variation in the Moho and the LAB. The crust and lithosphere are thinner in the east and thicker in the west. There is also a rapid drop of more than $100 \mathrm{mGal}$ Bouguer gravity anomaly across the DTGL. The DTGL also roughly coincides with the western termination of the $\sim 35 \mathrm{~km}$ thickening of the mantle transition zone, which is also revealed by $\mathrm{P}$ wave tomography (Chen and Pei 2010; Pei and Chen 2010). Based on the tomographic model, Chen regarded the DTGL as the west end of the big mantle wedge convection, and our results are in agreement with their explanations. These studies suggest that the mantle dynamics, lithospheric tectonics, and surface geology in the NE China are closely related. The primary features of the crustal and upper mantle discontinuities across the DTGL are in concord with those reported by Chen (Chen and Pei 2010) in the NCC. They also observed think lithosphere in the west part of NCC and thin lithosphere in the east with a rapid thickening of the lithosphere in the order of $20-40 \mathrm{~km}$ in DTGL. The concept of lithospheric thinning in the East Asia continent first raised from the study of NCC (Griffin et al. 1998; Menzies and Xu 1998) that the eastern portion of the North China Craton experienced widespread lithospheric rejuvenation since the late Mesozoic. The thick cratonic lithosphere lost a significant prorogation of its deep mantle keel (Griffin et al. 1998; Menzies and Xu 1998; Ren et al. 2002; Wu et al. 2003; Wu et al. 2003). Petrologic and isotopic studies also imply a thin lithosphere (Wu et al. 2003) in the NE China. Although the NCC and the NE China have gone through different evolution history, we still suggest that since late Mesozoic, the NCC and the NE China have probably 

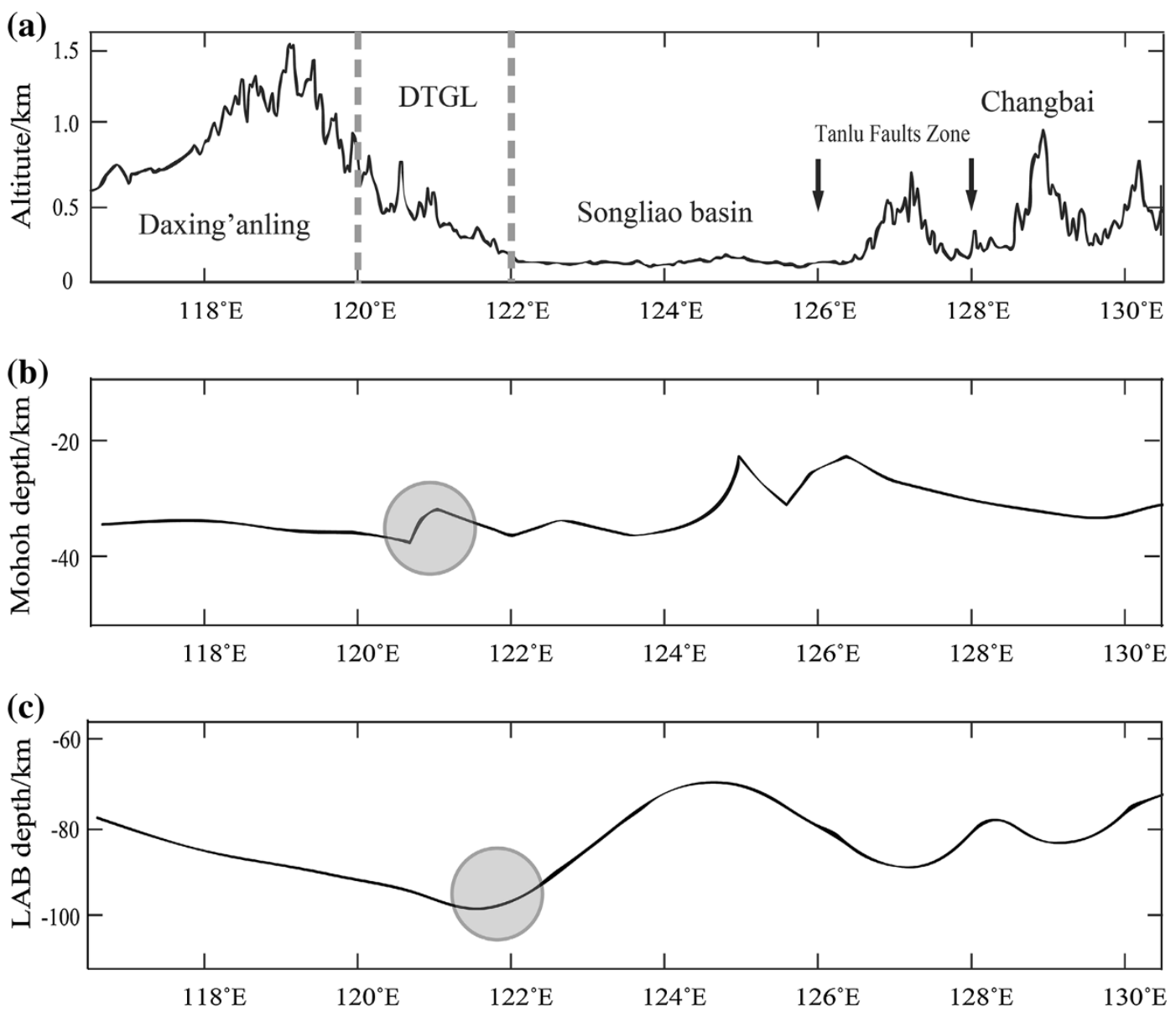

(d)

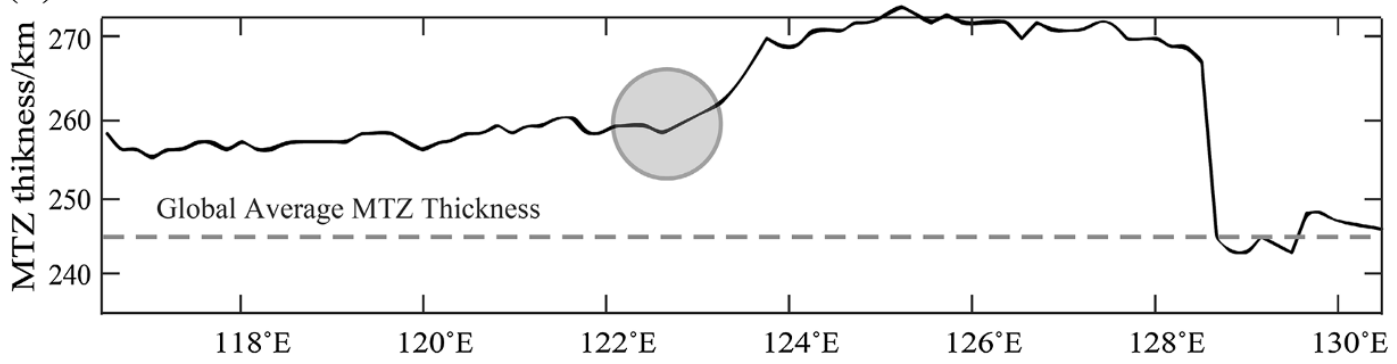

Fig. 7 Comparison between the Moho depth, LAB depth, and mantle transition zone thickness with the topographic variation. Gray dashed lines in $\mathbf{a}$ indicate the DTGL and gray circles in b-d represent the sharp change in the morphologies of different interfaces

experienced similar tectonic processes that dominantly affected the current surface geology. The subducted Pacific plate are believed to have played an important role in the tectonic evolution of both regions (Chen and Pei 2010; Ren et al. 2002).

\section{Conclusions}

Using $\mathrm{P}$ and $\mathrm{S}$ receiver function analyses with high quality waveform data recorded by 27 seismic stations, we observed detailed structures of crust, upper mantle, and mantle transition zone beneath the NNW profile of NE China. A relatively flat Moho $(\sim 37 \mathrm{~km})$ beneath the Daxing' anling region is observed, and there is about $4 \mathrm{~km}$ Moho offset at the DTGL. In the Songliao basin, the Moho is slightly shallower than that in the Daxing'anling region. The most striking feature is that the shallowest Moho is beneath the Tanlu faults rather than beneath the center of the basin. The complex Moho topography, especially its uplift of $\sim 5 \mathrm{~km}$ beneath the Tanlu faults, implies that the faults might penetrated deeply into the uppermost mantle, and facilitated the local mantle upwelling during the Cenozoic. The average LAB depth in the study region is 
shallower than the global continental average. There is a significant gradient of the lithospheric thickness at the DTGL. An arc-shaped LAB with its apex of at $\sim 65 \mathrm{~km}$ depth is observed by the migrated $S$ receiver functions in the basin. We believed that the thinned LAB is consistent with the large-scale rifting process occurred in the Mesozoic at the Songliao basin. The CCP stacking results of $\mathrm{P}$ receiver functions show the remarkable thickening $(\sim 35 \mathrm{~km})$ of the mantle transition zone between $123^{\circ} \mathrm{E}$ and $129^{\circ} \mathrm{E}$, which is consistent with the stagnant Pacific slab in the mantle transition zone revealed by the previous $\mathrm{P}$ wave tomography. The consistence of the crustal and upper mantle discontinuities with the surface topography at the DTGL suggest that the upper mantle tectonic evolution beneath the NE China and the surface geology in the region are closely related.

\section{References}

Ai Y, Zheng T, Xu W, He Y, Dong D (2003) A complex $660 \mathrm{~km}$ discontinuity beneath northeast China. Earth Planet Sci Lett 212(1):63-71

Bina CR, Helffrich G (1994) Phase transition Clapeyron slopes and transition zone seismic discontinuity topography. J Geophys Res: Solid Earth (1978-2012) 99(B8):15853-15860

Chen YJ, Pei S (2010) Tomographic structure of East Asia: II. Stagnant slab above $660 \mathrm{~km}$ discontinuity and its geodynamic implications. Earthq Sci 23(6):613-626

Chen L, Wen L, Zheng T (2005) A wave equation migration method for receiver function imaging: 1 theory. J Geophys Res 110(B11)

Chen L, Zheng T, Xu W (2006) A thinned lithospheric image of the Tanlu Fault Zone, eastern China: constructed from wave equation based receiver function migration. J Geophys Res 111(B9)

Chen L, Tao W, Zhao L, Zheng T (2008) Distinct lateral variation of lithospheric thickness in the Northeastern North China Craton. Earth Planet Sci Lett 267(1):56-68

Dueker KG, Sheehan AF (1997) Mantle discontinuity structure from midpoint stacks of converted $\mathrm{P}$ to $\mathrm{S}$ waves across the Yellowstone hotspot track. J Geophys Res 102(B4):8313-8327

Farra V, Vinnik L (2000) Upper mantle stratification by P and S receiver functions. Geophys J Int 141(3):699-712

Fukao Y, Widiyantoro S, Obayashi M (2001) Stagnant slabs in the upper and lower mantle transition region. Rev Geophys 39(3):291-323

Griffin W, Andi Z, O'reilly S, Ryan C (1998) Phanerozoic evolution of the lithosphere beneath the Sino-Korean Craton. Geodyn Ser 27:107-126

Hilde TW, Uyeda S, Kroenke L (1977) Evolution of the western Pacific and its margin. Tectonophysics 38(1):145-165

Hu W, Cai C, Wu Z, Li J (1998) Structural style and its relation to hydrocarbon exploration in the Songliao basin, Northeast China. Mar Pet Geol 15(1):41-55

Ito E, Takahashi E (1989) Postspinel transformations in the system $\mathrm{Mg} 2 \mathrm{SiO} 4-\mathrm{Fe} 2 \mathrm{SiO} 4$ and some geophysical implications. J Geophys Res 94(B8):10637-10646

Jackson I (1983) Some geophysical constraints on the chemical composition of the Earth's lower mantle. Earth Planet Sci Lett 62(1):91-103

Kennett B (1991) The removal of free surface interactions from threecomponent seismograms. Geophys J Int 104(1):153-163
Langston CA (1977) The effect of planar dipping structure on source and receiver responses for constant ray parameter. Bull Seismol Soc Am 67(4):1029-1050

Lei J, Zhao D (2005) P-wave tomography and origin of the Changbai intraplate volcano in Northeast Asia. Tectonophysics 397(3): 281-295

Li X, Yuan X (2003) Receiver functions in northeast Chinaimplications for slab penetration into the lower mantle in northwest Pacific subduction zone. Earth Planet Sci Lett 216(4):679-691

Li X, Kind R, Yuan X, Wölbern I, Hanka W (2004) Rejuvenation of the lithosphere by the Hawaiian plume. Nature 427(6977): $827-829$

Li X, Yuan X, et al (2007) The lithosphere-asthenosphere boundary beneath the western United States. Geophys J Int 170(2): $700-710$

Li Y, Wu Q, Pan J, Sun L (2012) S-wave velocity structure of Northeastern China from joint inversion of Rayleigh wave phase and group velocities. Geophys J Int 190(1):105-115

Ligorría JP, Ammon CJ (1999) Iterative deconvolution and receiverfunction estimation. Bull Seismol Soc Am 89(5):1395-1400

Liu H, Niu F (2011) Receiver function study of the crustal structure of Northeast China: seismic evidence for a mantle upwelling beneath the eastern flank of the Songliao Basin and the Changbaishan region. Earthq Sci 24(1):27-33

Liu J, Han J, Fyfe WS (2001) Cenozoic episodic volcanism and continental rifting in northeast China and possible link to Japan Sea development as revealed from K-Ar geochronology. Tectonophysics 339(3):385-401

Meng QR, Hu JM, Jin JQ, Zhang Y, Xu DF (2003) Tectonics of the late Mesozoic wide extensional basin system in the ChinaMongolia border region. Basin Res 15(3):397-415

Menzies MA, Xu Y (1998) Geodynamics of the North China craton. Geodyn Ser 27:155-165

Owens TJ, Nyblade AA, Gurrola H, Langston CA (2000) Mantle transition zone structure beneath Tanzania, East Africa. Geophys Res Lett 27(6):827-830

Pei S, Chen YJ (2010) Tomographic structure of East Asia: I. No fast (slab) anomalies beneath $660 \mathrm{~km}$ discontinuity. Earthq Sci 23(6):597-611

Ren J, Tamaki K, Li S, Junxia Z (2002) Late Mesozoic and Cenozoic rifting and its dynamic setting in Eastern China and adjacent areas. Tectonophysics 344(3):175-205

Ryberg T, Weber M (2000) Receiver function arrays: a reflection seismic approach. Geophys J Int 141(1):1-11

Shapiro N, Ritzwoller M (2002) Monte-Carlo inversion for a global shear-velocity model of the crust and upper mantle. Geophys $\mathbf{J}$ Int 151(1):88-105

Tian Z-Y, Han P, et al (1992) The Mesozoic-Cenozoic east China rift system. Tectonophys. 208(1):341-363

Wilson D, Aster R (2005) Seismic imaging of the crust and upper mantle using regularized joint receiver functions, frequencywave number filtering, and multimode Kirchhoff migration. J Geophys Res 110(B5)

Wu F-Y, Walker RJ, Ren X-W, Sun D-Y, Zhou X-H (2003) Osmium isotopic constraints on the age of lithospheric mantle beneath Northeastern China. Chem Geol 196(1):107-129

Wu Q, Li Y, Zhang R, Zeng R (2007) Receiver functions from autoregressive deconvolution. Pure Appl Geophys 164(11): 2175-2192

$\mathrm{Xu}$ Y-G (2001) Thermo-tectonic destruction of the Archaean lithospheric keel beneath the Sino-Korean Craton in China: evidence, timing and mechanism. Phys Chem Earth Part A 26(9):747-757

Xu YG, Chung SL, Ma J, Shi L (2004) Contrasting Cenozoic Lithospheric Evolution and Architecture in the Western and 
Eastern Sino-Korean Craton: constraints from Geochemistry of Basalts and Mantle Xenoliths. J Geol 112(5):593-605

Yang B-J, Mu S-M, et al (1996) Synthesized study on the geophysics of Manzhouli-Suifenhe geoscience transect, China. Acta Geophys Sinica 39:782-792

Yuan X, Ni J, Kind R, Mechie J, Sandvol E (1997) Lithospheric and upper mantle structure of southern Tibet from a seismological passive source experiment. J Geophys Res 102(B12):27491-27500

Yuan X, Kind R, Li X, Wang R (2006) The S receiver functions: synthetics and data example. Geophys J Int 165(2):555-564
Yue H, Chen YJ, Sandvol E, Ni J, Hearn T, Zhou S, Feng Y, Ge Z, Trujillo A, Wang Y (2012) Lithospheric and upper mantle structure of the Northeastern Tibetan Plateau. J Geophys Res 117(B5)

Zorin YA, Belichenko V, Turutanov EK, Kozhevnikov V, Ruzhentsev S, Dergunov A, Filippova I, Tomurtogoo O, Arvisbaatar N, Bayasgalan $T$ (1993) The south Siberia-central Mongolia transect. Tectonophysics 225(4):361-378 